\title{
TRPA1 Function in Skeletal Muscle Sensory Neurons Following Femoral Artery Occlusion
}

\author{
Jihong Xing ${ }^{a, b} \quad$ Jianhua Lib \\ aDepartment of Emergency Medicine, The First Hospital of Jilin University, Changchun, Jilin, China, \\ bPennsylvania State Heart \& Vascular Institute, The Pennsylvania State University, College of Medicine, \\ Hershey, PA, USA
}

\section{Key Words}

Muscle afferent nerve $\cdot$ TRPA1 $\bullet$ Peripheral arterial disease $\bullet$ Hindlimb ischemia

\begin{abstract}
Background/Aims: Transient receptor potential channel A1 (TRPA1) is engaged in amplified autonomic responses evoked by stimulation of muscle afferent nerves in rats with experimental peripheral arterial disease. The purposes of this study were to characterize current responses induced by activation of TRPA1 in dorsal root ganglion (DRG) neurons of control limbs and limbs with femoral artery occlusion. Methods: DRG neurons from rats were labeled by injecting the fluorescence tracer DiI into the hindlimb muscles and whole-cell patch clamp experiments were performed to determine TRPA1 currents. Results: Data show that AITC (a TRPA1 agonist) from the concentrations of $50 \mu \mathrm{M}$ to $200 \mu \mathrm{M}$ produces a dose-dependent increase of amplitudes of inward current responses. Notably, the peak current amplitude induced by AITC is significantly larger in DRG neurons of ligated limbs than that in control limbs. AITC-induced current responses are observed in small and medium size DRG neurons, and there is no difference in size distribution of DRG neurons between control limbs and ligated limbs. However, femoral occlusion increases the percentage of the AITC-sensitive DRG neurons as compared to control. AITC-induced currents in DRG neurons are significantly attenuated by exposure to $10 \mu \mathrm{M}$ of $\mathrm{HC}-030031$, a potent and selective inhibitor of TRPA1, in both control and femoral occlusion groups. In addition, capsaicin (a TRPV1 agonist) evokes a greater increase in the amplitude of AITC-currents in DRG neurons of ligated limbs than that in control limbs. Conclusions: A greater current response with activation of TRPA1 is developed in muscle afferent nerves when hindlimb arterial blood supply is deficient under ischemic conditions; and TRPV1 is partly responsible for augmented TRPA1 responses induced by arterial occlusion.

\section{Introduction}

Exercise increases sympathetic nerve activity (SNA) [1, 2], an effect which in turn increases arterial blood pressure (BP), heart rate (HR), myocardial contractility and

Jihong Xing and Jianhua Li 
peripheral vascular resistance. Two mechanisms, namely central command and the exercise pressor reflex, evoke this exercise-induced increase in SNA. Central command postulates a parallel and simultaneous increase in sympathetic and alpha motoneuron discharge $[3,4]$. The exercise pressor reflex postulates that thin fiber muscle afferent nerves (group III \&IV) innervating skeletal muscles are activated by contraction-induced mechanical and metabolic stimuli to elicit a reflex increase in SNA $[5,6]$.

Peripheral arterial disease (PAD) is atherosclerotic disease with a decrease in blood flow to the arteries of the lower extremities. In this disease, the most common symptom is intermittent claudication, which is worsened by intense exercise activity due to muscle ischemia but subsides at rest when the metabolic demand of the active muscles is low [7]. It was observed that both systolic and diastolic BP rise significantly in the patients with PAD than in the normal subjects during walking [8]. Furthermore, the exercise pressor reflex plays a crucial role in evoking the exaggerated BP response to walking in PAD patients [9]. Consistently, using a rat model of femoral artery ligation to study PAD in humans [10], prior studies have demonstrated that the SNA and BP responses to static muscle contraction as well as to stimulation of several muscle metabolic receptors are amplified in occluded rats compared with control rats $[11,12]$. Nevertheless, the underlying mechanisms by which femoral occlusion augments responsiveness of SNA and BP during activation of muscle mechanically and metabolically sensitive afferents remain to be determined.

Transient receptor potential channel A1 (TRPA1) is a member of branch A of the transient receptor potential (TRP) family of nonselective cation channels. This channel is expressed in the sensory neurons and is involved in acute and inflammatory pain [13-19]. TRPA1 acts as a sensory receptor in response to pungent and reactive chemicals such as allylisothiocyanate (AITC), allicin, cinnamaldehyde, formaldehyde, $\mathrm{N}$-methylmaleimide, and $\alpha, \beta$-unsaturated aldehydes $[13,19-21]$. TRPA1 also serve as a sensor of cold temperature and mechanical deformation $[16,18,19,22-25]$. In addition to pungent chemicals found in nature, endogenously generated molecules such as bradykinin, reactive oxygen species, and 4-hydroxynonenal that are produced during inflammation and oxidative stress, can activate TRPA1 [13, 25-27].

A prior study has demonstrated that intra-arterial injection of AITC, a TRPA1 agonist, into the hindlimb muscle circulation of healthy rats led to increases in SNA and BP via a reflex mechanism [28]. Also, this study has suggested that TRPA1 plays a role in regulating the metabolic component of the exercise pressor reflex. i.e., acid phosphate, bradykinin and arachidonic acid, which are accumulated in exercising muscles, are likely engaged in the role played by TRPA1 as endogenous stimuli. Our recent study has further demonstrated that TRPA1 in thin-fiber muscle afferents plays an important role in engagement in the amplified reflex SNA and BP responses observed in rats with femoral artery ligation [29].

Additionally, TRPA1 is generally found to co-express with TRPV1 receptor [30]. Many agonists i.e. black pepper and garlic extracts have been identified to activate both TRPA1and TRPV1 receptors, although their potency can vary [31, 32]. Our previous data demonstrate that the magnitude of TRPV1 response induced by capsaicin is greater in DRG neurons of limbs with femoral artery ligation [33]. Accordingly, in this report, we characterized current responses of TRPA1 and further examined the effects of prior activation of TRPV1 on TRPA1 responses in DRG neurons of control limbs and ligated limbs. We hypothesized that under circumstances of chronic muscle ischemia, the amplitude of current responses with stimulation of TRPA1 is greater. We further hypothesized that TRPV1 facilitates TRPA1 currents to a greater degree following muscle ischemia.

\section{Materials and Methods}

All animal experimental procedures were approved by the Institutional Animal Care and Use Committee of Pennsylvania State College of Medicine and complied with the National Institutes of Health (NIH) guidelines.

\section{KARGER}




\section{Cellular Physiology Cell Physiol Biochem 2017;42:2307-2317 \begin{tabular}{l|l|l} 
and Biochemistry Published online: August 17, 2017 & $\begin{array}{l}\text { (c) } 2017 \text { The Author(s). Published by S. Karger AG, Basel } \\
\text { www.karger.com/cpb }\end{array}$
\end{tabular}}

Xing et al.: TRPA1 in Dorsal Root Ganglion

\section{Labeling DRG Neurons Innervating Hindlimb Muscle}

Male Sprague-Dawley rats (4-6 weeks old) were anaesthetized by inhalation of an isoflurane-oxygen mixture (2-5\% isoflurane in $100 \%$ oxygen). The skin was incised and pulled away from underlying muscle tissue, and the fluorescent retrograde tracer Dil $(60 \mathrm{mg} / \mathrm{ml})$ was injected into the white portion of the gastrocnemius muscle [33, 34]. The injection volume of $1 \mu \mathrm{l}$ was administered, and injection was repeated three times at different locations. The injection needle was left in the muscle for 5-10 min to prevent leakage of tracer. The skin overlying the muscle was then sutured. The animals were returned to their cages for 4-5 days to permit the retrograde tracer to be transported to DRG neurons.

\section{Ligation of the Femoral Artery}

At twenty-four hours prior to the recording experiments, the rats that previously received DiI injections were anaesthetized with an isoflurane-oxygen mixture. Then, the femoral artery on one limb was surgically exposed, dissected, and ligated $\sim 3 \mathrm{~mm}$ distal to the inguinal ligament as previously described $[33,35]$. The same procedures were performed on the other limb except that a suture was placed below the femoral artery but was not tied; this served as the control.

\section{Examination of DRG Neurons Responsiveness}

The rats were anesthetized with an isoflurane oxygen mixture followed by cervical dislocation and decapitation. The L4-6 DRGs were quickly removed and transferred immediately into Dulbecco's modified Eagle's Medium (DMEM). The DRGs were minced, and the ganglion fragments were processed to obtain dissociated DRG neurons as described previously [33, 34]. The cell suspension was centrifuged to remove the supernatant, and the cell pellet was re-suspended in DMEM. The cells were then plated onto a 35-mm culture dish containing pre-coated coverslips.

Next, patch recordings were performed after dissociation [33, 34]. Neurons were first visualized using a combination of epifluorescent illumination and differential interference contrast (DIC, 20-40X) optics on an inverted microscope (Nikon TE2000). Under DIC, images of Dil-positive neurons were displayed on a video monitor. Neurons were patched in the whole-cell configuration and recorded at a holding potential of -70 mV using a MultiClamp 700B amplifier. Seals (1-10 G $\Omega$ ) between the glass electrode (2-5 M $\Omega$ resistance) and the cell were established in a modified Tyrode solution [33, 34]. After the whole-cell configuration was established, all experiments were conducted. Signals were acquired using the pClamp 9.0 software and experimental data were analyzed using the Clampfit software program. Neurons were considered AITCsensitive if AITC solution elicited an inward current of $>50 \mathrm{pA}$ in peak amplitude.

Drugs stored in stock solutions were diluted in extracellular solution immediately before being used and were held in a series of independent syringes connected to corresponding fused silica columns (inner diameter $200 \mu \mathrm{m}$ ) [33, 34]. The ends of the parallel columns were connected to a common silica column. The distance from the column mouth to the examined cell was $100 \mu \mathrm{m}$. Cells in the recording chamber were continuously bathed in Tyrode solution. The gravity-fed solutions containing each drug were delivered to the cells by controlling the corresponding valve switch (WP Instruments).

In the first experiment, the effects of TRPA1 agonist on current responses of DRG neurons of control limbs and ligated limbs were examined. Fifty, 100, $200 \mu \mathrm{M}$ and $1 \mathrm{mM}$ of AITC were applied onto DRG neurons for a period of $30 \mathrm{~s}$, respectively. In addition, HC-030031 (HC), a TRPA1 antagonist, was applied to examine activation of TRPA1. In this protocol, AITC was first delivered for $30 \mathrm{~s}$ and recordings were maintained to observe the full time course of AITC-evoked current responses of DRG neurons. After that, $10 \mu \mathrm{M}$ of HC was applied onto DRG neurons for 60s, followed by AITC for $30 \mathrm{~s}$. After $3 \mathrm{~min}$ of washout, AITC was delivered alone for $30 \mathrm{~s}$ to assess recovery data.

In another experiment, the effects of TRPV1 activation on responses of TRPA1-induced currents were examined. Fifty $\mu \mathrm{M}$ of AITC was first applied onto DRG neurons of control limbs and ligated limbs for $30 \mathrm{~s}$ to obtain current response. After intervals of $3 \mathrm{~min}$ washout, $1 \mu \mathrm{M}$ of capsaicin was perfused for $2 \mathrm{~s}$. Then, AITC was delivered for $30 \mathrm{~s}$ again after the inactivation of capsaicin-elicited current.

A total of 220 DRG neurons from control limbs and 138 DRG neurons from limbs with twenty-four hours of femoral artery ligation were included in this study. All DRG neurons used in this report were DiIpositive. At the end of each experiment, the gastrocnemius muscle was dissected to confirm that DiI was located in the white portion of the gastrocnemius muscle. Diameters of all neurons recorded were $<40 \mu \mathrm{m}$ (small and medium size). 


\begin{abstract}
Statistical Analysis
Experimental data were analyzed using one-way repeated measures analysis of variance (ANOVA). As appropriate, Tukey's post hoc tests were used. All values were presented as mean \pm SEM. For all analyses, differences were considered significant at $P<0.05$. All statistical analyses were performed using SPSS for Windows version 15.0.
\end{abstract}

\section{Results}

TRPA1-Mediated Whole Cell Currents in DRG Neurons

The four concentrations of AITC $(50 \mu \mathrm{M}, 100 \mu \mathrm{M}, 200 \mu \mathrm{M}$ and $1 \mathrm{mM}$ ) were used onto muscle DRG neurons to obtain TRPA1 currents (Fig. 1A\&B). AITC produced a dose-dependent increase in the amplitudes of inward current responses with the concentrations of $50 \mu \mathrm{M}$ to $200 \mu \mathrm{M}(P<0.05$ among three different concentrations). The peak amplitudes of AITC currents induced by $50 \mu \mathrm{M}$ to $200 \mu \mathrm{M}$ of AITC were 83.1 \pm $7.4 \mathrm{pA}(\mathrm{n}=15), 278.4 \pm 40.4 \mathrm{pA}$ $(\mathrm{n}=20)$ and $359.9 \pm 65.8 \mathrm{pA}$ $(\mathrm{n}=14)$, respectively. However, when $1 \mathrm{mM}$ of AITC was applied onto neurons, this did not evoke the greater amplitude of the inward current as compared with the current activated by $200 \mu \mathrm{M}$ of AITC (359.9 \pm 65.8 pA by $200 \mu \mathrm{M}$ of AITC, $\mathrm{n}=14$ to $354.6 \pm 63.6 \mathrm{pA}$ by $1 \mathrm{mM}$ of AITC, $\mathrm{n}=21, P>0.05$ vs. $200 \mu \mathrm{M}$ of AITC).

\section{Effects of Femoral Occlusion on TRPA1 Currents in DRG Neurons}

One hundred $\mu \mathrm{M}$ of AITC was selected to induce TRPA1 current responses in muscle DRG neurons of control limbs and ligated limbs. Fig. $2 A$ shows original traces of currents in DRG neurons innervating hindlimb muscle elicited by $100 \mu \mathrm{M}$ of AITC in a control limb and in a limb with femoral artery ligation. When compared with TRPA1 current responses in control limbs, femoral arterial occlusion induced greater peak inward current amplitudes $(278.4 \pm 40.4 \mathrm{pA}$ in 20 neurons of control limbs vs. $401.1 \pm 42.1 \mathrm{pA}$ in 22 neurons of ligated limbs, $P<0.05$ ) as shown by average data of Fig. $2 B$.

In addition, the DRG neurons recorded in control and arterial occlusion are all small and medium size. There was no difference in the average diameter of recorded DRG cells responding to AITC in both groups $(28.1 \pm 0.9 \mu \mathrm{m}$ in control, $\mathrm{n}=80$ to $29.1 \pm 0.8 \mu \mathrm{m}$ in ligation, $\mathrm{n}=83, P>0.05$ ) (Fig. 2C). However, the percentage of the AITC-responsive DRG neurons was greater after arterial occlusion $(58.0 \pm 4.3 \%)$ than that in the control $(43.1 \pm 5.5 \%, P<0.05$ vs. ligation group) (Fig. 2D).

Also, we examined the effects of the inhibitor of TRPA1, HC, [36], on evoked currents by AITC in both control group and femoral ligation group. Note that HC did not elicit any current 
Fig. 2. Effects of femoral arterial occlusion on TRPA 1-induced currents: A, Original traces of currents elicited by $100 \mu \mathrm{M}$ of AITC in DRG neurons of a control limb and a limb with femoral artery ligation. The amplitude of the current in a DRG neuron of the ligated limb is larger than that in a DRG neuron of the control limb.

$\mathrm{B}$, Averaged data show that femoral artery ligation resulted in the greater increase in amplitudes of currents elicited by $100 \mu \mathrm{M}$ of AITC. ${ }^{*} \mathrm{P}<0.05$ vs. control. C, Diameters of DRG neurons innervating muscle responding to AITC in control limbs and limbs with femoral arterial occlusion. Averaged data show that there was no significant difference in size of DRG neurons between control and ligation groups. D, Percentage of muscle DRG neurons responsive to $100 \mu \mathrm{M}$ of AITC in control and ligation groups. A larger percentage of DRG neurons responsive to AITC were observed after femoral artery ligation compared with control. $* \mathrm{P}<0.05$, vs. control.

Fig. 3. AITC-induced currents in DRG neurons were antagonized by a prior blocking of TRPA1 with 10 $\mu \mathrm{M}$ of HC-030031 (HC) in both control and ligation groups: A, Typical traces showing the effects of HC on AITC-activated currents. B, Averaged data show that AITC-induced currents in muscle DRG neurons were blocked by prior exposure to $10 \mu \mathrm{M}$ of HC. Note that $50 \mu \mathrm{M}$ of AITC was used to evoke currents and the antagonizing effects of $\mathrm{HC}$ were reversible in both control and ligations groups.

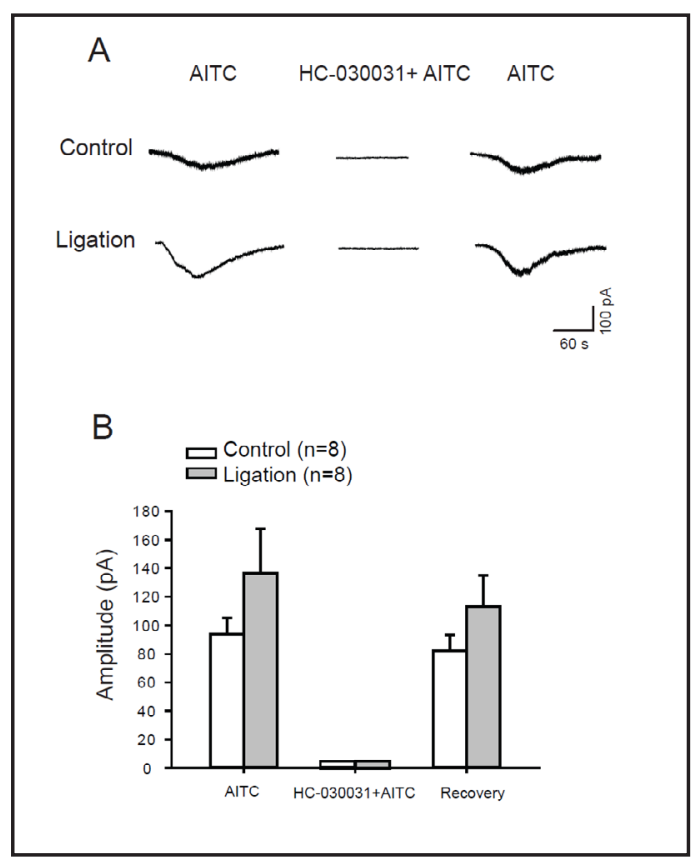

response per se. However, AITC currents in DRG neurons were completely attenuated by exposure to $10 \mu \mathrm{M}$ of $\mathrm{HC}$ (Fig. 3, A\&B). This antagonizing effect of $10 \mu \mathrm{M}$ of HC on AITC currents was reversible in both experimental groups (in control: $93.9 \pm 11.5 \mathrm{pA}$ before $\mathrm{HC}$ to $82.1 \pm 11.2 \mathrm{pA}$ after $\mathrm{HC}, \mathrm{n}=8, P>0.05$; in ligation: $136.6 \pm 30.9 \mathrm{pA}$ before $\mathrm{HC}$ to $113.3 \pm 21.8$ $\mathrm{pA}$ after $\mathrm{HC}, \mathrm{n}=8, P>0.05$ ). 
Fig. 4. Prior activation of TRPV1 by capsaicin increases TRPA1 responses to AITC: A, Original traces show the effects of prior application of $1 \mu \mathrm{M}$ of capsaicin on AITC-induced currents in DRG neurons of a control limb and a ligated limb. B, Averaged data show that $2 \mathrm{~s}$ treatment of capsaicin amplified the amplitude of AITCactivated currents in muscle DRG neurons of both control and ligation group. ${ }^{*} \mathrm{P}<0.05$ compared with before capsaicin. C, The percentage of augmented amplitude of AITCinduced currents by capsaicin appeared to be greater in DRG neurons of ligated limbs as compared with that in DRG neurons of control limbs. ${ }^{*} \mathrm{P}<0.05$ vs. control. AITC was first applied for $30 \mathrm{~s}$ to obtain control. After intervals of 3 min washout, $1 \mu \mathrm{M}$ of capsaicin was perfused for $2 \mathrm{~s}$. After the inactivation of capsaicin-elicited current, AITC was delivered for $30 \mathrm{~s}$ again. Note that the scales in A are applied for AITC-elicited currents.

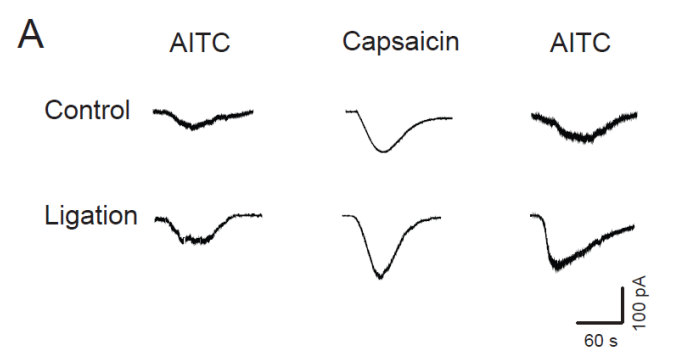

B

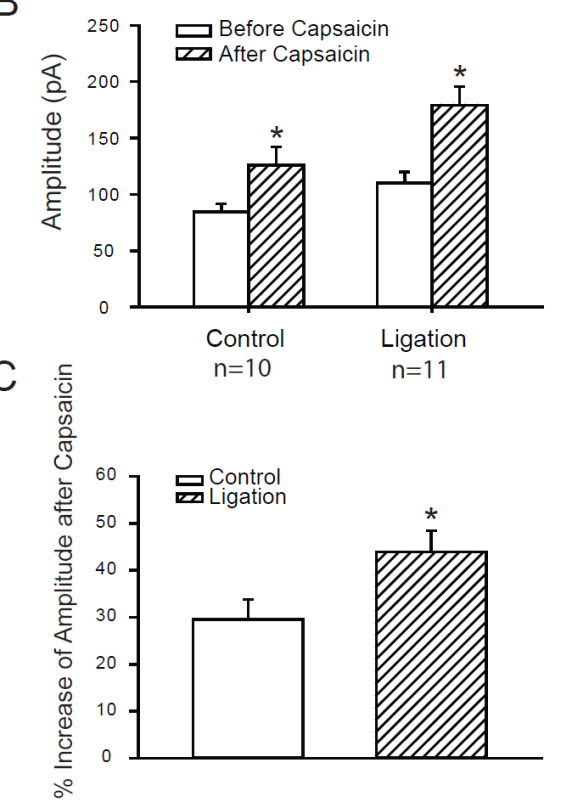

Prior Activation of TRPV1 Augments TRPA1 Response

We examined whether a prior exposure to $1 \mu \mathrm{M}$ of capsaicin could augment the current responses elicited by $50 \mu \mathrm{M}$ of AITC in muscle DRG neurons of both control limbs and ligated limbs (Fig. $4 A-C$ ). In AITC-responsive DRG neurons of control, pretreatment of capsaicin increased the amplitude of AITC-activated currents (84.5 $\pm 7.3 \mathrm{pA}$ before capsaicin to 110.1 \pm 9.7 pA after capsaicin, $\mathrm{n}=10, P<0.05$ ) (Fig. $4 A \& B$ ). Similarly, in AITC-responsive DRG neurons obtained from limbs with femoral artery ligation, prior application of capsaicin also accentuated the amplitude of the currents induced by $50 \mu \mathrm{M}$ of AITC $(125.9 \pm 16.3 \mathrm{pA}$ before capsaicin to $179.2 \pm 16.4 \mathrm{pA}$ after capsaicin, $\mathrm{n}=11, P<0.05$ ) (Fig. $4 A \& B$ ). Nevertheless, the percentage of amplified amplitude by capsaicin was significantly higher in DRG neurons of ligated limbs ( $43.9 \pm 4.5 \%, P<0.05 v s$. control) than that in DRG neurons of control limbs $(29.6 \pm 4.2 \%)$ (Fig. 4 C). Note that in both control and ligation groups all of the neurons responsive to $50 \mu \mathrm{M}$ of AITC were also responding to $1 \mu \mathrm{M}$ of capsaicin.

\section{Discussion}

Given that DRG cells are the primary sensory innervations to group III and IV fibers afferent nerves, expression and characteristics of sensory receptors (i.e., TRPA1) in DRG neurons are generally examined to study receptor physiology. Previous studies suggest 


\section{Cellular Physiology Cell Physiol Biochem 2017;42:2307-2317 \\ \begin{tabular}{ll|l} 
DOI: 10.1159/000480003 & O 2017 The Author(s). Published by S. Karger AG, Basel \\
www.karger.com/cpb
\end{tabular}}

Xing et al.: TRPA1 in Dorsal Root Ganglion

that the glycolytic muscle plays a major role in reflex muscle responses evoked by static contraction [37]. A study using electrophysiological methods has also demonstrated that DRG neurons with nerve endings in the white portion of the gastrocnemius muscle develop greater inward current responses to metabolic stimulation such as protons and capsaicin (a TRPV1 agonist) $[34,38]$. Therefore, in the current report, AITC-induced currents with TRPA1 activation were recorded on rat DRG neurons innervating the white portion of the gastrocnemius muscles identified by retrograde labeling with the fluorescent dye DiI. Furthermore, we characterized TRPA1 currents in muscle DRG neurons of control limbs and ligated limbs.

In general, AITC and cinnamaldehyde are currently used as TRPA1 agonists in experiments [39]. Cinnamaldehyde has been considered to activate only a smaller population of sensory neurons [40]. Therefore, in the current study, we used AITC to evoke TRPA1current responses in DRG neurons innervating muscle of control limbs and limbs with twenty-four hours of femoral artery occlusion in rats.

AITC was applied from $10 \mu \mathrm{M}$ to $1000 \mu \mathrm{M}$ sequentially onto the DRG neurons and data of this previous study demonstrated that a value of EC50 for AITC is $173 \mu \mathrm{M}$ and the saturating concentration is about $1 \mathrm{mM}$ [41]. Also, a brief application (20-50 s) of AITC at $200 \mu \mathrm{M}$ has been shown to induce responses that were readily reversible, but continuous application of higher concentrations $(>500 \mu \mathrm{M})$ of AITC induced a complete desensitization of the current response [41]. Thus, the similar concentrations of AITC were used in our current study. Consistent with these previous findings, results of the present study showed that AITC produced a dose-dependent increase in amplitudes of inward current responses from the concentrations of $50 \mu \mathrm{M}$ to $200 \mu \mathrm{M}$. However, when $1 \mathrm{mM}$ of AITC was applied, this failed to augment the amplitude of the inward current as compared with the current activated by 200 $\mu \mathrm{M}$ of AITC. Moreover, our results showed that AITC-induced currents in DRG neurons were completely attenuated by exposure to HC, a TRPA1inhibitor, in both control and femoral ligation groups and the antagonizing effect of $\mathrm{HC}$ was reversible.

Notably, we found that the peak current amplitude induced by AITC was larger in muscle DRG neurons of ligated limbs than that in control limbs, and that arterial occlusion increased the percentage of the AITC-responsive DRG neurons. In our previous study [29], the protein levels of TRPA1 were amplified in DRG of ligated limbs using western blot analysis, and an increase in the number of TRPA1 expressing DRG neurons supplying metabolically sensitive afferent nerves of C-fiber (group IV) was also observed after femoral ligation using immunocytochemical methods. In accordance with results of this previous study, data of the present study showed that AITC-responsive DRG neurons were all small and medium size and the number of AITC-responsive DRG neurons was increased by femoral occlusion. In addition, the greater peak AITC current amplitude in DRG neurons of ligated limbs was observed in the present study and this was likely due to amplified TRPA1 expression as seen previously [29].

TRPA1 has a similar structure to TRPV1 receptor, but with numerous ankyrin repeats in its amino (N) terminal [42]. TRPA1 has been shown to be co-expressed with TRPV1 [19]. Many agonists have been identified to activate both TRPA1 and TRPV1 receptors [31, 32]. AITC can activate porcine TRPV1 [43]. Note that application of AITC in the micromolar range did not significantly affect currents recorded in TRPV1-transfected HEK293 cells. However, TRPV1 contributes to the DRG neuron responses to $3 \mathrm{mM}$ of mustard oil [44]. Likewise, a previous study has shown that cell membrane staining of TRPA1 increased upon with treatment of $1 \mu \mathrm{M}$ of capsaicin [45]. Also, this prior study has demonstrated that activation of TRPV1 by capsaicin that was accompanied with localized calcium influx acutely increased TRPA1 membrane surface expression while TRPV1 levels were unchanged [45]. Our published work showed that a higher density of TRPV1 immunostaining was induced within DRG neurons of rats with femoral artery occlusion when compared with that in control rats, and that the arterial occlusion insult induced greater peak of inward current amplitudes in DRG neurons to capsaicin [33]. In the current study, $1 \mu \mathrm{M}$ of capsaicin applied onto DRG neurons augmented the amplitude of current responses elicited by AITC in both experimental 
groups. The percentage of amplitude increase by capsaicin was greater in DRG neurons of ligated limbs that that in control limbs. Thus, we speculate that artery occlusion-enhanced expression and responses of TRPV1 in DRG neurons likely induced a greater calcium influx and increased TRPA1 membrane surface expression in engagement in the role played by TRPA1 observed in our current study.

An important issue is what endogenous muscle metabolites within ischemic muscles augment responses of sensory nerves'TRPA1. In addition to pungent chemicals found in nature, endogenously generated molecules such as bradykinin, reactive oxygen species, and 4-hydroxynonenal produced during inflammation and oxidative stress can activate TRPA1 $[13,25,26]$. Acid phosphate, bradykinin and arachidonic acid, which are accumulated in contracting muscles, are considered as potential endogenous stimuli engaged in the exercise pressor reflex $[28,46]$. Our study has also reported that femoral artery occlusion amplifies blood pressure responses to stimulation of muscle afferent nerves and increased responses are attenuated by blocking kinin B2 receptor [47]. Thus, we speculate that some muscle metabolites and their respective receptors such as bradykinin/kinin B2 receptor may play a role in engagement in amplified sensory responses of TRPA1 as a modulator after femoral artery occlusion.

Nevertheless, a prior study has shown that in healthy rats, intra-arterially injection of AITC into the hindlimb muscle circulation led to increases in sympathetic activity via a reflex pathway [28]. Also, this prior study has demonstrated that TRPA1 plays a role in regulating sympathetic activity via stimulating the metabolic component of the exercise pressor reflex. When the similar dosages AITC was selected to stimulate TRPA1 on muscle afferent nerves and results of our recent work showed that greater sympathetic and pressor responses were evoked by arterial injection of AITC into the hindlimb muscles in ligated rats than those responses in control rats [29].

PAD can lead to severe limb ischemia. Thus, the classic discomfort syndrome of PAD is termed "intermittent claudication" which is characterized by pain in lower limbs that especially occurs during walking [48]. Note that muscular pain plays a significant component in fibromyalgia and other chronic pain conditions [49]. In general, enhanced expression and function of nociceptive ion channel such as TRPA1 and TRPV1 are critical in regulating pain [50]. In the present study, we observed that response of TRPA1 was increased by femoral occlusion and the effects were amplified by the prior TRPV1 activation. These conditions shed light as to the possible causes of pain associated with PAD. Nonetheless, if these changes reflect in the central terminals of the DRG neurons likely leading to synaptic plasticity still need to be determined.

\section{Conclusion}

Results of the current study for the first time demonstrated that DRG current response to activation of TRPA 1 is exaggerated following femoral artery occlusion, and that augmented responses are mostly observed in small/medium diameter of DRG neurons innervating the hindlimb muscles. In addition, stimulation of TRPV1 receptors augments TRPA1 responses of DRG neurons to a greater degree after femoral artery occlusion, indicating that TRPV1 is partly responsible for augmented TRPA1 responses. This also suggests that a functional interaction in TRPV1 and TRPA1 in muscle sensory nerves likely contributes to the amplified sympathetic responsiveness observed in PAD. Overall, our findings support the notion that TRPA1 in muscle afferent nerves contributes to augmented sympathetic responsiveness via the metabolic component of the exercise pressor reflex when blood supply to the hindlimb muscles is insufficient as observed in PAD. This pathophysiological basis may further help to aim at a potential therapeutic approach for improvement of blood flow in PAD patients. 


\section{Cellular Physiology Cell Physiol Biochem 2017;42:2307-2317 \begin{tabular}{l|l|l} 
DOI: 10.1159/000480003 & $\begin{array}{l}\text { (c) } 2017 \text { The Author(s). Published by S. Karger AG, Basel } \\
\text { www.karger.com/cpb }\end{array}$ \\
\hline
\end{tabular}}

Xing et al.: TRPA1 in Dorsal Root Ganglion

\section{Acknowledgements}

This study was supported by NIH R01 HL090720, American Heart Association Established Investigator Award 0840130N and NIH P01 HL096570.

\section{Disclosure Statement}

None.

\section{References}

1 Sinoway L, Prophet S, Gorman I, Mosher T, Shenberger J, Dolecki M, Briggs R, Zelis R: Muscle Acidosis during Static Exercise Is Associated with Calf Vasoconstriction. J Appl Physiol 1989;66:429-436.

2 Victor RG, Bertocci L, Pryor S, Nunnally R: Sympathetic nerve discharge is coupled to muscle cell pH during exercise in humans. J Clin Invest 1988;82:1301-1305.

-3 Goodwin GM, McCloskey DI, Mitchell JH: Cardiovascular and respiratory responses to changes in central command during isometric exercise at constant muscle tension. J Physiol (London) 1972;226:173-190.

4 Waldrop TG, Eldridge FL, Iwamoto GA, Mitchell JH: Central neural control of respiration and circulation during exercise. Chapter 9; in (Rowell LB, and Shepherd JT, eds) Handbook of Physiology - Section 12, Exercise: Regulation and Integration of Multiple Systems. New York, Oxford University Press, 1996, vol. p.^pp. 333-380.

5 Mitchell JH, Kaufman MP, Iwamoto GA: The exercise pressor reflex: its cardiovascular effects, afferent mechanisms, and central pathways. Annu Rev Physiol 1983;45:229-242.

6 Kaufman MP, Forster HV: Reflexes controlling circulatory, ventilatory and airway responses to exercise. Chapter 10; in (Rowell LB, and Shepherd JT, eds) Handbook of Physiology - Section 12, Exercise: Regulation and Integration of Multiple Systems. New York, Oxford University Press, 1996, vol. p.^pp. 381447.

7 Rejeski WJ, Tian L, Liao Y, McDermott MM: Social cognitive constructs and the promotion of physical activity in patients with peripheral artery disease. J Cardiopul Rehab Prev 2008;28:65-72.

-8 Baccelli G, Reggiani P, Mattioli A, Corbellini E, Garducci S, Catalano M, Omboni S: Hemodynamic changes in the lower limbs during treadmill walking in normal subjects and in patients with arteriosclerosis obliterans. Angiol 1997;48:795-803.

-9 Baccelli G, Reggiani P, Mattioli A, Corbellini E, Garducci S, Catalano M: The exercise pressor reflex and changes in radial arterial pressure and heart rate during walking in patients with arteriosclerosis obliterans. Angiol 1999;50:361-374.

$>10$ Waters RE, Terjung RL, Peters KG, Annex BH: Preclinical models of human peripheral arterial occlusive disease: implications for investigation of therapeutic agents. J Appl Physiol 2004;97:773-780.

11 Li J, Xing J: Muscle afferent receptors engaged in augmented sympathetic responsiveness in peripheral artery disease. Front Exer Physiol 2012;3:247.

12 Tsuchimochi H, McCord JL, Hayes SG, Koba S, Kaufman MP: Chronic femoral artery occlusion augments exercise pressor reflex in decerebrated rats. Am J Physiol Heart Cir Physiol 2010;299:H106-113.

13 Bandell M, Story GM, Hwang SW, Viswanath V, Eid SR, Petrus MJ, Earley TJ, Patapoutian A: Noxious cold ion channel TRPA1 is activated by pungent compounds and bradykinin. Neuron 2004;41:849-857.

-14 Bautista DM, Jordt S-E, Nikai T, Tsuruda PR, Read AJ, Poblete J, Yamoah EN, Basbaum AI, Julius D: TRPA1 mediates the inflammatory actions of environmental irritants and proalgesic agents. Cell 2006;124:12691282.

15 Katsura H, Obata K, Mizushima T, Yamanaka H, Kobayashi K, Dai Y, Fukuoka T, Tokunaga A, Sakagami M, Noguchi K: Antisense knock down of TRPA1, but not TRPM8, alleviates cold hyperalgesia after spinal nerve ligation in rats. Exp Neurol 2006;200:112-123.

-16 Kwan KY, Allchorne AJ, Vollrath MA, Christensen AP, Zhang D-S, Woolf CJ, Corey DP: TRPA1 contributes to cold, mechanical, and chemical nociception but is not essential for hair-cell transduction. Neuron 2006;50:277-289. 


\section{Cellular Physiology Cell Physiol Biochem 2017;42:2307-2317 \begin{tabular}{ll|l} 
DOI: 10.1159/000480003 & $\begin{array}{l}\text { O 2017 The Author(s). Published by S. Karger AG, Basel } \\
\text { www.karger.com/cpb }\end{array}$
\end{tabular}}

Xing et al.: TRPA1 in Dorsal Root Ganglion

17 Macpherson LJ, Dubin AE, Evans MJ, Marr F, Schultz PG, Cravatt BF, Patapoutian A: Noxious compounds activate TRPA1 ion channels through covalent modification of cysteines. Nature 2007;445:541-545.

18 Obata K, Katsura H, Mizushima T, Yamanaka H, Kobayashi K, Dai Y, Fukuoka T, Tokunaga A, Tominaga M, Noguchi K: TRPA1 induced in sensory neurons contributes to cold hyperalgesia after inflammation and nerve injury. J Clin Invest 2005;115:2393-2401.

19 Story GM, Peier AM, Reeve AJ, Eid SR, Mosbacher J, Hricik TR, Earley TJ, Hergarden AC, Andersson DA, Hwang SW, McIntyre P, Jegla T, Bevan S, Patapoutian A: ANKTM1, a TRP-like channel expressed in nociceptive neurons, is activated by cold temperatures. Cell 2003;112:819-829.

-20 Bautista DM, Movahed P, Hinman A, Axelsson HE, Sterner O, Hogestatt ED, Julius D, Jordt S-E, Zygmunt PM: Pungent products from garlic activate the sensory ion channel TRPA1. PNAS 2005;102:12248-12252.

21 Jordt S-E, Bautista DM, Chuang H-H, McKemy DD, Zygmunt PM, Hogestatt ED, Meng ID, Julius D: Mustard oils and cannabinoids excite sensory nerve fibres through the TRP channel ANKTM1. Nature 2004;427:260-265.

22 Kindt KS, Viswanath V, Macpherson L, Quast K, Hu HZ, Patapoutian A, Schafer WR: Caenorhabditis elegans TRPA-1 functions in mechanosensation. Nat Neurosci 2007;10:568-577.

23 Nagata K, Duggan A, Kumar G, Garcia-Anoveros J: Nociceptor and hair cell transducer properties of TRPA1, a channel for pain and hearing. J Neurosci 2005;25:4052-4061.

24 Sawada Y, Hosokawa H, Hori A, Matsumura K, Kobayashi S: Cold sensitivity of recombinant TRPA1 channels. Brain Res 2007;1160:39-46.

25 Trevisani M, Siemens J, Materazzi S, Bautista DM, Nassini R, Campi B, Imamachi N, Andre E, Patacchini R, Cottrell GS, Gatti R, Basbaum AI, Bunnett NW, Julius D, Geppetti P: 4-Hydroxynonenal, an endogenous aldehyde, causes pain and neurogenic inflammation through activation of the irritant receptor TRPA1. PNAS 2007;104:13519-13524.

-26 Bessac BF, Sivula M, von Hehn CA, Escalera J, Cohn L, Jordt S-E: TRPA1 is a major oxidant sensor in murine airway sensory neurons. J Clin Invest 2008;118:1899-1910.

27 Kim HJ, Wie J, So I, Jung MH, Ha KT, Kim BJ: Menthol Modulates Pacemaker Potentials through TRPA1 Channels in Cultured Interstitial Cells of Cajal from Murine Small Intestine. Cell Physiol Biochem 2016;38:1869-1882.

28 Koba S, Hayes SG, Sinoway LI: Transient receptor potential A1 channel contributes to activation of the muscle reflex. Am J Physiol Heart Circ Physiol 2011;300:H201-H213.

29 Xing J, Lu J, Li J: TRPA1 mediates amplified sympathetic responsiveness to activation of metabolically sensitive muscle afferents in rats with femoral artery occlusion. Front Physiol 2015;6:249.

30 Kobayashi K, Fukuoka T, Obata K, Yamanaka H, Dai Y, Tokunaga A, Noguchi K: Distinct expression of TRPM8, TRPA1, and TRPV1 mRNAs in rat primary afferent neurons with adelta/c-fibers and colocalization with trk receptors. J Comp Neurol 2005;493:596-606.

-31 Koizumi K, Iwasaki Y, Narukawa M, Iitsuka Y, Fukao T, Seki T, Ariga T, Watanabe T: Diallyl sulfides in garlic activate both TRPA1 and TRPV1. Biochem Biophy Res Commun 2009;382:545-548.

-32 Okumura Y, Narukawa M, Iwasaki Y, Ishikawa A, Matsuda H, Yoshikawa M, Watanabe T: Activation of TRPV1 and TRPA1 by black pepper components. Biosci Biotech Biochem 2010;74:1068-1072.

33 Xing J, Gao Z, Lu J, Sinoway LI, Li J: Femoral artery occlusion augments TRPV1-mediated sympathetic responsiveness. Am J Physiol Heart Cir Physiol 2008;295:H1262-H1269.

34 Xing J, Sinoway L, Li J: Differential responses of sensory neurones innervating glycolytic and oxidative muscle to protons and capsaicin. J Physiol 2008;586:3245-3252.

35 Liu J, Gao Z, Li J: Femoral artery occlusion increases expression of ASIC3 in dorsal root ganglion neurons. Am J Physiol Heart Cir Physiol 2010;299:H1357-1364.

-36 McNamara CR, Mandel-Brehm J, Bautista DM, Siemens J, Deranian KL, Zhao M, Hayward NJ, Chong JA, Julius D, Moran MM, Fanger CM: TRPA1 mediates formalin-induced pain. PNAS 2007;104:13525-13530.

37 Wilson LB, Dyke CK, Parsons D, Wall PT, Pawelczyk JA, Williams RS, Mitchell JH: Effect of skeletal muscle fiber type on the pressor response evoked by static contraction in rabbits. J Appl Physiol 1995;79:17441752.

38 Xing J, Li J: The Role Played by Adenosine in Modulating Reflex Sympathetic and Pressor Responses Evoked by Stimulation of TRPV1 in Muscle Afferents. Cell Physiol Biochem 2016;40:39-48.

-39 Bodkin JV, Brain SD: Transient receptor potential ankyrin 1: emerging pharmacology and indications for cardiovascular biology. Acta Physiol 2011;203:87-98. 


\section{Cellular Physiology Cell Physiol Biochem 2017;42:2307-2317

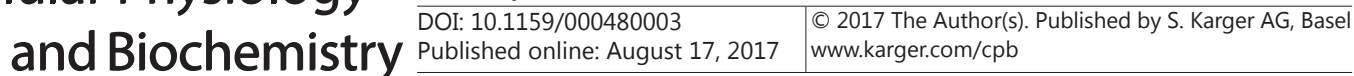

Xing et al.: TRPA1 in Dorsal Root Ganglion

40 Huang J, Zhang X, McNaughton PA: Modulation of temperature-sensitive TRP channels. Sem Cell Deve Biol 2006;17:638-645.

41 Raisinghani M, Zhong L, Jeffry JA, Bishnoi M, Pabbidi RM, Pimentel F, Cao D-S, Evans MS, Premkumar LS: Activation characteristics of transient receptor potential ankyrin 1 and its role in nociception. Am J Physiol Cell Physiol 2011;301:C587-600.

42 Jaquemar D, Schenker T, Trueb B: An ankyrin-like protein with transmembrane domains is specifically lost after oncogenic transformation of human fibroblasts. J Biol Chem 1999;274:7325-7333.

-43 Ohta T, Imagawa T, Ito S: Novel agonistic action of mustard oil on recombinant and endogenous porcine transient receptor potential V1 (pTRPV1) channels. Biochem Pharmacol 2007;73:1646-1656.

44 Everaerts W, Gees M, Alpizar YA, Farre R, Leten C, Apetrei A, Dewachter I, van Leuven F, Vennekens R, De Ridder D, Nilius B, Voets T, Talavera K: The capsaicin receptor TRPV1 is a crucial mediator of the noxious effects of mustard oil. Cur Biol 2011;21:316-321.

45 Schmidt M, Dubin AE, Petrus MJ, Earley TJ, Patapoutian A: Nociceptive signals induce trafficking of TRPA1 to the plasma membrane. Neuron 2009;64:498-509.

46 Xing J, Li J: Bradykinin Contributes to Sympathetic and Pressor Responses Evoked by Activation of Skeletal Muscle Afferents P2X in Heart Failure. Cell Physiol Biochem 2016;39:2101-2109.

47 Lu J, Xing J, Li J: Bradykinin B2 receptor contributes to the exaggerated muscle mechanoreflex in rats with femoral artery occlusion. Am J Physiol Heart Circ Physiol 2013;304:H1166-H1174.

48 Fowkes FG, Aboyans V, Fowkes FJ, McDermott MM, Sampson UK, Criqui MH: Peripheral artery disease: epidemiology and global perspectives. Nat Rev Cardiol 2017;14:156-170.

49 Okifuji A, Hare BD: Management of fibromyalgia syndrome: review of evidence. Pain Ther 2013;2:87-104.

50 Julius D: TRP channels and pain. Annu Rev Cell Dev Biol 2013;29:355-384. 